\title{
SUFICIENCIA AMOSTRAL PARA COLETAS DE SERAPILHEIRA ACUMULADA SOBRE O SOLO EM Pinus elliottii ENGELM, Eucalyptus sp. E FLORESTA ESTACIONAL DECIDUAL ${ }^{1}$
}

Isabel Sandra Kleinpaul ${ }^{2}$, Mauro Valdir Schumacher ${ }^{3}$, Eleandro José Brun ${ }^{4}$, Flávia Gizele König Brun ${ }^{5}$ e Joel Juliano Kleinpaul ${ }^{6}$

\begin{abstract}
RESUMO - O presente estudo objetivou determinar a suficiência amostral para coletas de serapilheira acumulada sobre o solo em povoamentos de Pinus elliottii, Eucalyptus sp., ambos plantados no Campus da Universidade Federal de Santa Maria e em uma área de Floresta Estacional Decidual (FED) localizada no Morro do Elefante, Santa Maria, RS. Para a realização do estudo, foram coletadas 100 amostras de serapilheira por floresta, com o auxílio de uma moldura quadrada de $25 \mathrm{~cm}$ de lado, totalizando 300 amostras, as quais foram separadas nas seguintes frações: acículas ou folhas, galhos, estruturas reprodutivas, cascas e resíduos. Com base nos pesos de matéria seca de cada fração, realizou-se a análise estatística dos dados, visando à estabilização dos valores do coeficiente de variação (CV\%). Para Pinus elliottii, a maior contribuição na formação da serapilheira foi dada pelas acículas, com 57,2\%; em Eucalyptus sp., isso ocorreu com os galhos (38,8\%) e na FED, novamente com as folhas, que representaram $49,6 \%$ da serapilheira. No Pinus elliottii, o maior CV\% se deu nos resíduos, seguido de estruturas reprodutivas. Em Eucalyptus sp., o maior CV\% foi encontrado em cascas, seguido de galhos. Na FED, as cascas tiveram o maior CV\%. A suficiência amostral necessária para Pinus elliottii foi de 40, sendo esse o povoamento que necessitou de menos amostras para estabilizar o CV\%. Em Eucalyptus sp., a suficiência amostral foi de 70, enquanto na FED foram necessárias 80 amostras.
\end{abstract}

Palavras-chave: Experimentação florestal, ciclagem de nutrientes e coeficiente de variação.

\section{ADEQUATE SAMPLING FOR COLLECTION OF LITTER ACCUMULATED ON THE SOIL IN Pinus elliottii ENGELM, Eucalyptus sp. AND SEASONAL DECIDUOUS FOREST}

\begin{abstract}
This study determined the sample sufficiency for the collection of litter accumulated on the soil, in Pinus elliottii and Eucalyptus sp. stands, planted in the Campus of the Federal University of Santa Maria and a Seasonal Deciduous Forest, located at the "Morro do Elefante", Santa Maria - RS. To carry out this study, 100 samples were collected per site, using a square frame $\left(25 \mathrm{~cm}^{2}\right)$, totaling 300 samples. The samples were separated in the following fractions: needles or leaves, branches, reproductive structures, barks and wastes. Based on the dry weights of each fraction, a statistical analysis was carried out, aiming the stabilization of the coefficient of variation (CV\%). For Pinus elliotti, "needles" was the fraction that contributed
\end{abstract}

\footnotetext{
${ }^{1}$ Recebido em 10.05.2004 e aceito para publicação em 10.08.2005.

${ }^{2}$ Engenheira Florestal formada pela UFSM - Santa Maria - RS. <isabelsk@ibest.com.br>, Tel. (0xx55)9967-5292.

${ }^{3}$ DCFl/CCR/UFSM. 97105-900 Santa Maria - RS. E-mail: <schuma@ ccr.ufsm.br>. Bolsista do CNPq.

${ }^{4}$ Engenheiro Florestal - Doutorando do Programa de Pós-Graduação em Engenharia Florestal - CCR-UFSM. Santa Maria - RS. E-mail: <eleandrojbrun@mail.ufsm.br>. Bolsista da CAPES.

${ }^{5}$ Engenheira Florestal - Mestranda do PPGEF-CCR-UFSM. Santa Maria - RS. Bolsista do CNPq.

${ }^{6}$ Engenheiro Florestal - Mestrando do PPGEF-CCR-UFSM. Santa Maria - RS. Bolsista da CAPES.
} 
the most, 57.2\%; for the Eucalyptus sp., the branches contributed with 38.8\%; and for the Seasonal Deciduous Forest the leaves contributed with 46.9\%. The highest CV\% in Pinus elliottii was for the wastes, followed by the reproductive structures. In Eucalyptus sp. the highest CV\% was for barks, followed by branches. In the Seasonal Deciduous Forest, the barks had the highest CV\%. The sample sufficiency for Pinus elliotti was 40, so this stand needed fewer samples to stabilize the CV\%. For Eucalyptus sp. the sample sufficiency was 70 , and in the Seasonal Deciduous Forest 80 samples were needed.

Keywords: Forest experimentation, nutrient cycling and coefficient of variation.

\section{INTRODUÇÃO}

A serapilheira é considerada todo o material recémcaído no solo de uma floresta, constituindo-se de folhas, cascas, galhos, frutos e outras partes. Sua deposição varia em função da tipologia vegetal e da condição climática. Vários fatores, abióticos e bióticos, afetam a produção de serapilheira, como tipo de vegetação, altitude, latitude, precipitação, temperatura, regimes de luminosidade, relevo, deciduidade, estágio sucessional, disponibilidade hídrica e características do solo (FIGUEIREDO FILHO et al., 2003).

Vibrans e Seveganani (2000) afirmaram que estudos sobre produção e decomposição de serapilheira em florestas são bastante numerosos, havendo, porém, dificuldades na comparação dos dados, devido a variações das metodologias utilizadas, como: a definição das frações da serapilheira, o tempo de realização da amostragem, o intervalo de coleta, a área, a forma, a altura e a disposição dos coletores e a temperatura de secagem do material, além das variações do sítio como tipologia florestal e estádio sucessional.

Quando se analisam os dados obtidos, a precisão experimental é de suma importância, pois esses dados serão comparados com outros trabalhos científicos e usados como referência.

Para Pimentel-Gomes (1985), o coeficiente de variação (CV\%) dá idéia de precisão do experimento. Geralmente, a variação dos dados experimentais pode ser expressa por três medidas de dispersão: o erropadrão da média, a variância $\left(\mathrm{s}^{2}\right)$ ou desvio-padrão (s) e o coeficiente de variação (CV\%). O CV\%, definido como o valor em porcentagem da média, é a medida estatística mais utilizada pelos pesquisadores na avaliação da precisão de experimentos. Essa variável estatística tem a vantagem de permitir a comparação da precisão entre experimentos sem a necessidade de igualdade de unidades, pois é expresso em porcentagem (AMARAL et al.,1997).

R. Árvore, Viçosa-MG, v.29, n.6, p.965-972, 2005
O objetivo do presente estudo foi determinar a suficiência amostral, para coletas de serapilheira acumulada sobre o solo em uma área de Floresta Estacional Decidual e em povoamentos de Pinus elliottii e Eucalyptus sp.

\section{MATERIAL E MÉTODOS}

\subsection{Caracterização das áreas de estudo}

O município de Santa Maria situa-se nas coordenadas $29^{\circ} 41^{\prime}$ de latitude sul e $53^{\circ} 42^{\prime}$ de longitude oeste. O clima é subtropical úmido, do tipo "Cfa", segundo a classificação de Köppen (MORENO, 1961), caracterizado por temperatura média anual entre 17,9 e $19,2^{\circ} \mathrm{C}$. As chuvas são bem distribuídas, sendo a precipitação média anual entre 1.400 e $1.760 \mathrm{~mm}$.

O solo da área dos dois primeiros povoamentos pertence à Unidade de Mapeamento São Pedro, classificado como Argissolo Vermelho distrófico arênico, de textura média, relevo suavemente ondulado e substrato arenito, apresentando solos profundos, avermelhados, friáveis e bem drenados e com textura superficial arenosa. São ácidos e pobres em matéria orgânica. Na Floresta Estacional Decidual, o solo da área pertence à Unidade de Mapeamento Charrua, classificado como Neossolo Litólico eutrófico chernossólico, textura média, relevo montanhoso e substrato basalto, sendo solos pouco desenvolvidos, rasos e moderadamente drenados, com afloramento de rochas (STRECK et al., 2002).

O povoamento de Pinus elliottii Engelm estudado encontra-se com 21 anos de idade, o qual foi plantado em espaçamento de 2,00 m x 2,50 m. Ao longo da rotação o mesmo já sofreu duas intervenções de desrama (aos 6 e 11 anos) e desbastes seletivos de baixa intensidade, aos 10 e 17 anos, encontrando-se o povoamento, aos 21 anos, ainda com uma densidade de árvores relativamente alta, sendo nítida a competição das copas 
das árvores por espaço, na época da realização deste estudo. O povoamento de Eucalyptus sp. encontrase com 12 anos de idade. O mesmo foi plantado em espaçamento de 2,00 m x 2,50 m, não tendo sofrido, até o momento, nenhuma intervenção de desrama ou desbaste.

Ambos os povoamentos foram implantados com aração e gradagem em área total, sem a realização de adubação no plantio ou de cobertura. No sub-bosque destes povoamentos há ocorrência eventual de regeneração natural das espécies principais (pinus e eucalipto) e também de espécies nativas de Floresta Estacional Decidual, como Eugenia uniflora L., Eugenia rostrifolia Legr., Cabralea canjerana (Vell.) Mart., Cedrella fissilis Vell., Casearia sylvestris Sw., Matayba elaeagnoides Radlk. e também algumas gramíneas e pteridófitas, ressaltando-se porém, que a maior parte do sub-bosque apresenta apenas serapilheira acumulada. A altitude média dos povoamentos é de $138 \mathrm{~m}$, estando localizados dentro do Campus da Universidade Federal de Santa Maria (UFSM), em Santa Maria, RS.

A área de Floresta Estacional Decidual estudada encontra-se recobrindo o Morro do Elefante, numa altitude média de $460 \mathrm{~m}$, a cerca de $5 \mathrm{~km}$ do Campus da UFSM. Afloresta em questão é um mosaico de diversos estágios de sucessão, tendo em vista o uso da área como lavoura em anos anteriores e o seu abandono progressivo. Para este estudo, foram selecionados estágios de sucessão vegetal que foram desde capoeirões (em torno de 20 anos sem cultivo) até florestas secundárias altas (em torno de 60 anos sem uso). A idade aproximada dos estágios sucessionais foi obtida através de consulta a antigos moradores das proximidades.

A vegetação típica ocorrente nos morros que circundam o município de Santa Maria é a Floresta Estacional Decidual, que em geral apresenta cinco estratos vegetativos: o estrato superior, o estrato médio, o estrato das arvoretas, o estrato arbustivo e o estrato herbáceo, e esses dois últimos se encontram mesclados no interior da floresta. Conta-se, ainda, com a presença de epífitas e lianas (KLEIN, 1983).

Segundo Machado e Longhi (1990), o Morro do Elefante possui composição florística heterogênea, com grande número de espécies arbóreas, igual a 67, distribuindo-se em 57 gêneros e 30 famílias botânicas. A área basal por hectare é de $36,3 \mathrm{~m}^{2}$. Segundo esses autores, as espécies Trichilia clausseni C. DC., Cupania vernalis Camb., Nectandra megapotamica (Spreng.) Mez, Enterolobium contortisiliquum (Vell.) Morong, Alchornea triplinervia (Spreng.) Müll. Arg., Prunus subcoriacea Koehne e Allophylus edulis (St. Hil.) Radlk., são as mais características e importantes da associação, apresentado o maio IVI (Índice de Valor de Importância). As espécies mais destacadas no estrato superior são Nectandra megapotamica, Cordia trichotoma (Vell.) Arrab. Ex Steud., Ficus luschnatiana (Miq.) Miq., Alchornea triplinervia e Enterolobium contortisiliquum. No estrato médio e inferior, as espécies Trichilia clausseni, Cupania vernalis, Urera baccifera (L.) Gaudich. e Casearia sylvestris Sw. predominam. A espécie Cupania vernalis foi a que apresentou maior abundância na regeneração, com cerca de 9.500 indivíduos/ha.

\subsection{Metodologia}

Foram coletadas, de forma aleatória, 100 amostras em cada floresta (Pinus elliottii, Eucalyptus sp. e Floresta Estacional Decidual) de serapilheira acumulada sobre o solo, com o auxílio de uma moldura de ferro quadrada com $25 \mathrm{~cm}$ de lado. Após a coleta, as amostras foram acondicionadas em embalagens plásticas devidamente identificadas e encaminhadas para o Laboratório de Ecologia Florestal do Departamento de Ciências Florestais da UFSM, onde o material foi separado nas seguintes frações: acículas ou folhas, galhos, estruturas reprodutivas, casca e resíduos (outros materiais encontrados na serapilheira ou não identificados). As amostras foram secadas em estufa de circulação e renovação de ar a $75^{\circ} \mathrm{C}$ por 72 horas, estabilizandose o peso dessas amostras nesse período de secagem e, então, pesadas em balança de precisão $(0,01 \mathrm{~g})$.

Para realização da análise dos dados foi utilizado o programa Microsoft Excel 2000, em que foram calculados a média, o desvio-padrão e o coeficiente de variação. Os cálculos foram realizados nas diferentes intensidades amostrais.

Para a definição da suficiência amostral, empregaramse os métodos de análise gráfica e Teste t. Na análise gráfica foram observadas as curvas de CV (\%) das frações e da serapilheira total nas diversas intensidades amostrais, sendo a intensidade amostral indicada aquela em que a curva de CV\% se estabilizou. O teste t foi realizado a partir da intensidade amostral estipulada no ponto de estabilização da curva, com o uso do desvio-

R. Árvore, Viçosa-MG, v.29, n.6, p.965-972, 2005 
padrão comum (Sc) entre as duas intensidades amostrais comparadas no teste, através da equação:

$$
\begin{aligned}
& S c=\sqrt{\frac{\left[\left(n_{1}-1\right) * s_{1}^{2}\right]+\left[\left(n_{2}-1\right) * s_{2}^{2}\right]}{n_{1}+n_{2}-2}} \\
& \text { O valor de " } \mathrm{t} \text { " foi calculado pela fórmula: }
\end{aligned}
$$

$$
t_{c a l}=\left[\left(\bar{x}_{1}-\bar{x}_{2}\right) / S c\right] * \sqrt{\frac{n_{1}+n_{2}}{n_{1} * n_{2}}}
$$

Com o valor do t calculado nas diferentes frações e na serapilheira total, este valor foi comparado com o t tabelado, em que se estipularam as seguintes hipóteses:

* t cal $\geq \mathrm{t}$ tab, rejeita-se Ho, houve variação significativa entre as médias provenientes das diferentes intensidades amostrais.

* t cal < t tab, não se rejeita Ho, não houve variação significativa entre as médias das demais intensidades amostrais, demonstrando que tal intensidade é ideal para coleta.

\section{RESULTADOS E DISCUSSÃO}

\subsection{Material formador da serapilheira}

O material formador da serapilheira do Pinus elliottii era constituído principalmente por acículas; em Eucalyptus sp., a predominância foi de galhos e, na Floresta Estacional Decidual, a fração principal foi a de folhas. Na Tabela 1 podem ser visualizados os valores de serapilheira acumulada, nas diferentes frações, sobre o solo, nas três áreas de estudo.

No povoamento de Pinus elliotti, a fração que teve maior contribuição para com a formação da serapilheira foi de acículas, com 57,2\%. Esse material apresenta decomposição lenta, devido ao seu alto teor de lignina, o que dificulta a ação dos microrganismos decompositores. Em Eucalyptus sp., o maior acúmulo sobre o solo foi de galhos, com 38,8\%. Povoamentos de eucalipto caracteristicamente sofrem um processo mais intenso de desrama natural, em relação a outras espécies, como as do gênero Pinus, e isso propicia maior acúmulo de galhos sobre o solo. Na Floresta Estacional Decidual, as folhas foram as principais contribuintes na formação da serapilheira, com 49,6\%, apesar de essa fração apresentar uma decomposição mais rápida em relação aos galhos; por exemplo, a produção de material foliar pelas árvores é superior à das demais frações.

Uma importante influência na quantidade de serapilheira acumulada sobre o solo foi dada pela época do ano em que foram realizadas as coletas, as quais ocorreram, no caso do povoamento de Pinus elliotti, no início de setembro; na Floresta Estacional Decidual, no final de setembro; e no Eucalyptus sp., em início de novembro. Essa época do ano é característica de maior queda de folhas senescentes, entre setembro e dezembro.

Figueiredo Filho et al. (2003), em avaliação estacional da deposição de serapilheira em uma Floresta Ombrófila Mista localizada no sul do Estado do Paraná, constataram que as folhas foram responsáveis pela maior parte da serapilheira produzida pela floresta, seguindo-se os galhos e resíduos, produzindo, em média, 4,40 $\mathrm{Mg} \mathrm{ha}^{-1}$ de folhas, 2,1 $\mathrm{Mg} \mathrm{ha}^{-1}$ de galhos e 1,3 $\mathrm{Mg} \mathrm{ha}^{-1}$ de resíduos. A deposição estacional de serapilheira seguiu a ordem decrescente primavera>inverno > verão>outono.

Tabela 1 - Serapilheira acumulada sobre o solo nas suas referidas frações e no total em cada floresta, em $\mathrm{Mg}_{\mathrm{g}} \mathrm{ha}^{-1}$ e porcentagem. Santa Maria, RS, 2004

Table 1 - Litter accumulated on the soil in their respective fractions and in the total per each forest, in $\mathrm{Mg}$ ha ${ }^{-1}$ and percentage. Santa Maria, RS 2004

\begin{tabular}{lccccc}
\hline Espécie & \multicolumn{5}{c}{ Frações $\left(\mathrm{Mg} \mathrm{ha}^{-1}\right)$} \\
\cline { 2 - 6 } & Acíc./Folhas & Galhos & Reprodutivos & Cascas & Resíduos \\
\hline Pinus & $12,53 \mathrm{a}$ & $3,65 \mathrm{~b}$ & $3,49 \mathrm{a}$ & $0,54 \mathrm{~b}$ & $1,69 \mathrm{a}$ \\
elliottii & $(57,2 \%)$ & $(16,7 \%)$ & $(15,7 \%)$ & $(2,5 \%)$ & $(7,7 \%)$ \\
Eucalyptus & $4,17 \mathrm{~b}$ & $4,53 \mathrm{a}$ & $0,41 \mathrm{~b}$ & $1,41 \mathrm{a}$ & $1,11 \mathrm{~b}$ \\
$\quad$ sp. & $(36,2 \%)$ & $(38,8 \%)$ & $(3,4 \%)$ & $(12,1 \%)$ & $(9,5 \%)$ \\
Floresta Est. & $4,00 \mathrm{~b}$ & $3,01 \mathrm{~b}$ & $0,16 \mathrm{~b}$ & $0,60 \mathrm{~b}$ & $0,29 \mathrm{c}$ \\
Decidual & $(49,6 \%)$ & $(37,3 \%)$ & $(2,0 \%)$ & $(7,4 \%)$ & $(3,6 \%)$ \\
\hline
\end{tabular}

* Médias não seguidas da mesma letra, na vertical, diferem entre si, pelo teste de Tukey a 5\% de probabilidade de erro. 
Esses aspectos também já foram relatados por autores que estudaram a deposição de serapilheira em área de Floresta Estacional Decidual (BRUN et al., 2001). Esses autores, ao relacionarem fatores climáticos à deposição de serapilheira em diferentes estágios sucessionais de uma área de Floresta Estacional Decidual no Rio Grande do Sul, concluíram que o principal mecanismo que desencadeia o processo de deposição de maior quantidade de serapilheira na primavera é a detenção do crescimento provocada pelo inverno, funcionando outros fatores, como o maior índice de chuvas no primeiro período citado, bem assim com o vento e o aumento da temperatura como processos auxiliares na deposição do material já senescente.

\subsection{Análise estatística dos dados}

A análise estatística dos dados obtidos das coletas de serapilheira de Pinus elliottii, Eucalyptus sp. e Floresta Estacional Decidual mostrou a existência de variabilidade por fração e para toda a serapilheira acumulada por floresta, a cada 10 amostras coletadas.

Constatou-se que os menores coeficientes de variação (CV\%), em Pinus elliottii (20,5 a 31,5\%), ocorreram em acículas, com uma média alta e um desviopadrão baixo, resultando num menor valor de CV\%, em relação aos encontrados nas demais frações constituintes da serapilheira. Os maiores CV\% (130,2 a $207,0 \%$ ) foram verificados nos resíduos, por apresentarem média baixa e desvio-padrão alto, sendo a fração em que se encontraram materiais em diferentes proporções nas amostras coletadas e mais materiais diversos que não se enquadram em nenhuma das frações, a não ser como resíduos (raízes ou materiais não identificados). Na intensidade amostral de 90 e 100, os maiores coeficientes de variação ocorreram nas estruturas reprodutivas $(136,0 \%)$, pois na maioria das amostras não se encontrou essa fração e, naquelas onde estiveram presentes, obtiveram um peso considerável, o que fez a média ser menor que o desviopadrão, aumentando o CV\%.

O menor coeficiente de variação, para coletas de serapilheira de Eucalyptus sp., foi nas folhas (15,2 a $29,5 \%$ ), onde o valor da média observada nas diferentes intensidades amostrais se encontrava bem acima do desvio-padrão, resultando num baixo CV\%. Os maiores coeficientes de variação foram verificados em galhos, nas 10 e 20 amostras (60,9 e 70,4\%), em que a espessura dos galhos variou, incrementando a variabilidade dos pesos e, em conseqüência disso, aumentando o CV\%. Com intensidade amostral de 50, o maior coeficiente de variação foi para resíduos $(64,4 \%)$. Com 30, 40, 60, 70, 80, 90 e 100 amostras, o maior CV\% foi para fração casca $(62,5$ a $86,8 \%)$, pois esse material é encontrado em abundância nas proximidades dos troncos, mas, devido à aleatoriedade das coletas, algumas amostras apresentaram grande e, outras, uma pequena quantidade de cascas, com essa variabilidade causando aumento do coeficiente de variação.

Na Floresta Estacional Decidual, o menor coeficiente de variação $(\mathrm{CV} \%)$ ocorreu na serapilheira total $(26,1 \%)$, com 10 amostras. Nas demais intensidades amostrais, o menor coeficiente de variação se encontrou em folhas (19,0 a 46,0\%), pois essa fração é a que contribui com a maior porcentagem na formação da serapilheira, sendo a média alta e o desvio-padrão baixo, ocasionando o menor CV\%, em comparação com as demais frações. Os maiores CV\% foram verificados em resíduos, na intensidade amostral de 10 (121,2\%), em que foi encontrado material que não pertencia a nenhuma fração das mencionadas anteriormente, aumentando o coeficiente de variação. Nas demais intensidades amostrais, o maior CV\% foi constatado nas cascas (170,6 a 216,7\%), em que se observou grande variabilidade nas amostras coletadas, encontrando-se nesta fração o maior desviopadrão em relação à média, aumentando o CV\%

Como pôde ser observado, nos povoamentos estudados o CV\% teve variabilidade entre as frações que compõem a serapilheira acumulada sobre o solo, pois cada fração contribui com quantidades diferentes de material para a formação da serapilheira.

Figueiredo Filho et al. (2003) avaliaram a deposição estacional de serapilheira em uma Floresta Ombrófila Mista no sul do Estado do Paraná (Tabela 2), onde se observa que os maiores CV\% ocorreram nos galhos, em todas as estações, pois estes variam na espessura e, em conseqüência, dão grande variabilidade ao peso desses galhos.

\subsection{Suficiência amostral}

Nas Figuras 1, 2 e 3 estão representadas as intensidades amostrais de cada fração de Pinus elliottii, Eucalyptus sp. e Floresta Estacional Decidual, com seus devidos coeficientes de variação. Pode-se observar que, onde o CV\% se estabilizou em todas as frações, esse foi o número de amostras recomendado para coletas futuras, ou seja, servirá de parâmetro para novos estudos.

R. Árvore, Viçosa-MG, v.29, n.6, p.965-972, 2005 
Tabela 2 - Análise estatística dos dados por estação do ano e fração de serapilheira, com a finalidade de verificar a variabilidade por fração e em toda a serapilheira produzida

Table 2 - Statistical analysis of data per season and litter fraction, to verify the variability per fraction and in the total litter produced

\begin{tabular}{lcccc}
\hline \multirow{2}{*}{ Estação } & Frações & $\bar{x}\left(\mathrm{~g} \mathrm{~m}^{-2}\right)$ & $\mathrm{s}\left(\mathrm{g} \mathrm{m}^{-2}\right)$ & $\mathrm{CV} \%$ \\
\hline \multirow{2}{*}{ Primavera } & Folhas & 148,66 & 53,19 & 35,78 \\
& Galhos & 54,01 & 29,07 & 53,83 \\
& Miscelânea & 40,67 & 19,07 & 46,90 \\
& Total & 243,34 & 78,09 & 32,09 \\
\hline \multirow{4}{*}{ Verão } & Folhas & 94,94 & 64,61 & 68,06 \\
& Galhos & 49,24 & 38,11 & 77,39 \\
& Miscelânea & 35,80 & 19,42 & 54,24 \\
& Total & 179,98 & 106,77 & 59,32 \\
\hline \multirow{3}{*}{ Outono } & Folhas & 69,00 & 34,83 & 50,48 \\
& Galhos & 40,13 & 78,59 & 195,82 \\
& Miscelânea & 24,77 & 22,80 & 92,05 \\
& Total & 133,90 & 107,70 & 80,43 \\
\hline \multirow{4}{*}{ Inverno } & Folhas & 128,23 & 54,89 & 42,80 \\
& Galhos & 62,99 & 71,89 & 114,13 \\
& Miscelânea & 25,25 & 15,56 & 61,64 \\
& Total & 216,47 & 110,75 & 51,16 \\
\hline
\end{tabular}

Em que: $\bar{x}=$ média, $\mathrm{s}=$ desvio-padrão e $\mathrm{CV} \%=$ coeficiente de variação. Fonte: Figueiredo Filho et al. (2003).

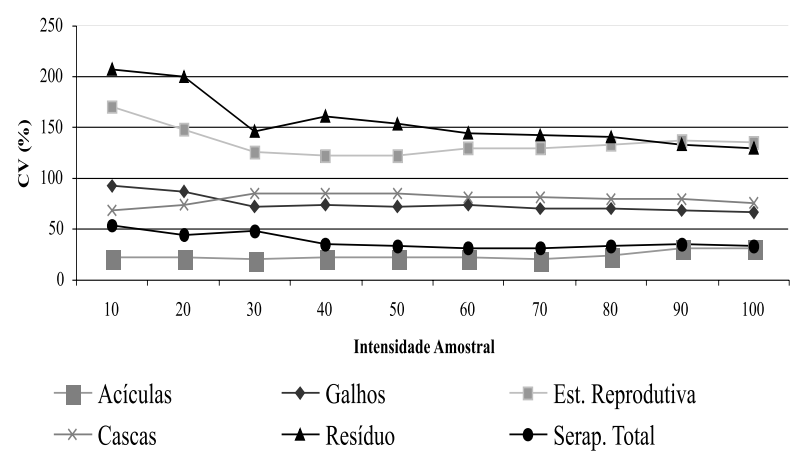

Figura 1 - Determinação da suficiência amostral de serapilheira de Pinus elliottii, levando-se em consideração a estabilização do CV\%.

Figure 1 - Determination of sample sufficiency for Pinus elliotti litter, considering the stabilization of the coefficient of variation (CV\%).

Na Figura 1 estão representadas as frações que compõem a serapilheira do Pinus elliottii, em que estas estão com os respectivos coeficientes de variação, podendo ser observado que, à medida que aumenta a intensidade amostral, o CV\% vai diminuindo até se estabilizar.

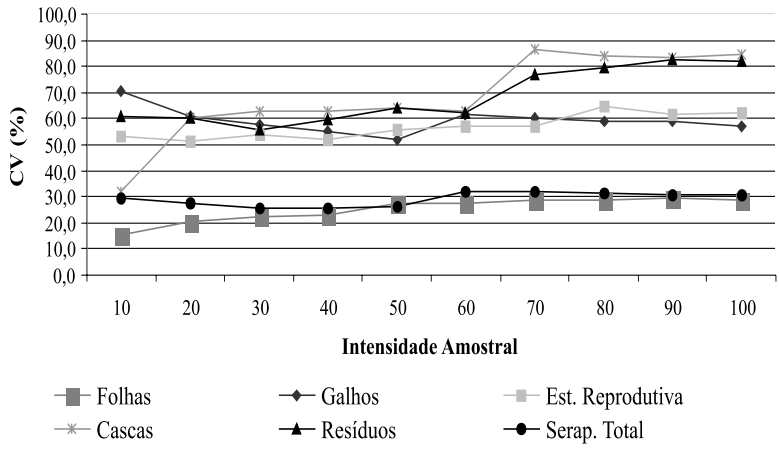

Figura 2 - Determinação da suficiência amostral de Eucalyptus sp., levando-se em consideração a estabilização do CV\%.

Figure 2-Determination of sample sufficiency for Eucapyptus sp., considering the stabilization of the coefficient of variation ( $\mathrm{CV} \%)$.

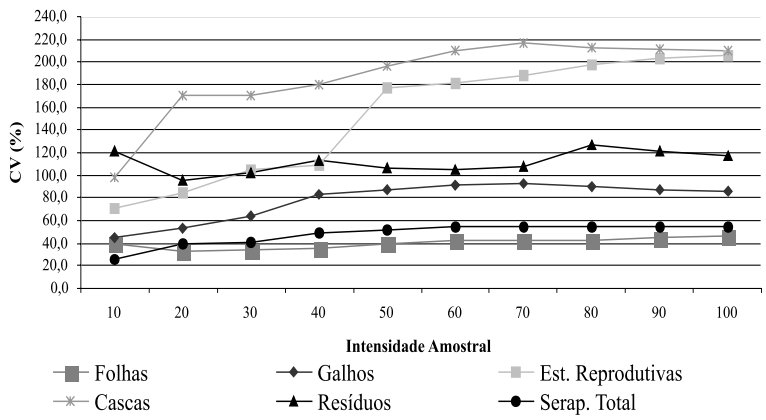

Figura 3 - Determinação da suficiência amostral de uma floresta nativa, levando-se em consideração a estabilização do CV\%.

Figure 3 -Determination of adequate sampling for native forest, considering the stabilization of the coefficient of variation $(C V \%)$.

Resíduos e estruturas reprodutivas foram as frações que mais variaram, mas, à medida que se aumentou a intensidade amostral, essas foram baixando seu CV\%, estabilizando em 40 amostras. As demais frações mantiveram uma tendência de estabilização. Para uma intensidade amostral de 40, tem-se uma suficiência amostral para coletas de serapilheira acumulada sobre o solo em povoamentos de Pinus elliottii.

Na Figura 2, no povoamento de Eucalyptus sp., cascas e resíduos foram as frações que mais variaram, em que as cascas tiveram um pico na intensidade amostral de 10 para 20 amostras, pois houve uma heterogeneidade na quantidade de cascas amostradas, estabilizando-se em 60 amostras, e novamente teve um pico em 70 amostras, estabilizando-se novamente. 
Os resíduos se mantiveram estáveis até 60 amostras, em que aumentou seu CV\% até 70 amostras. As demais frações não tiveram grande variabilidade, e há uma suficiência amostral com uma intensidade de 70 amostras, pois após se manteve estável. Esse valor é considerado adequado para essa espécie do povoamento estudado, não se podendo afirmar que todas as espécies do gênero Eucalyptus têm o mesmo comportamento, ou seja, a mesma suficiência amostral em coletas de serapilheira acumulada sobre o solo, pois tem características diferenciadas umas das outras.

Na Figura 3 estão representadas as frações que compõem a serapilheira, em que estas estão com os respectivos coeficientes de variação. Os dados da Floresta Estacional Decidual são de interpretação polêmica, pois, à medida que aumentou a intensidade amostral, juntamente aumentou a variabilidade. Esta é devida, justamente, por ser uma floresta nativa, onde se encontram diversas espécies, que contribuem, de forma desigual, com a formação da serapilheira depositada sobre o solo.

Nessa floresta, as frações que mais variaram foram as cascas e as estruturas reprodutivas, e nas primeiras a maior variação ocorreu entre 10 e 20 amostras e nas últimas, entre 40 e 50 amostras, sendo difícil conseguir a estabilização, a qual foi, porém, alcançada com uma intensidade amostral de 80 . Os resíduos e os galhos sofreram variações, pois continham galhos de várias espessuras e nos resíduos se encontravam materiais diferenciados, mas também ocorreu estabilização com uma intensidade amostral de 80 .

Complementando a indicação da intensidade amostral, foi realizado um teste $\mathrm{t}$, comparando as médias, duas a duas, com base nas diversas intensidades amostrais usadas, em que foi confirmada a suficiência amostral de coletas de serapilheira acumulada sobre o solo, nos três povoamentos estudados, ou seja, comprovou-se que a análise gráfica estava correta.

Em Pinus elliottii foi comparada a intensidade amostral de 40 com as demais intensidades amostrais, todas apresentando o $t$ calculado $<\mathrm{t}$ tabelado, rejeitandose Ho, no entanto não houve variação entre as médias das demais coletas, o que confirma que em Pinus elliottii, nas condições do estudo, uma intensidade amostral de 40 é suficiente para coletas de serapilheira acumulada sobre o solo.

Em Eucalyptus sp., mesmo com uma variação brusca em cascas, a intensidade amostral de 70 se mostrou suficiente, pois não houve variação em relação às demais coletas, em que todas tiveram o t calculado $<\mathrm{t}$ tabelado, rejeitando H0, tendo-se em Eucalyptus sp. uma boa representatividade em coletas de serapilheira acumulada sobre o solo, com uma intensidade amostral de 70 .

A Floresta Estacional Decidual foi a que necessitou de mais amostras para ter uma suficiência amostral, devido à heterogeneidade da floresta. Mesmo com as variações bruscas que ocorreram com as frações cascas e estruturas reprodutivas, houve estabilização comprovada pela análise estatística. O teste t confirmou que na floresta natural em questão, com 80 amostras, há uma suficiência para coletas de serapilheira acumulada sobre o solo.

No povoamento de Pinus elliottii, a moldura usada de $25 \mathrm{~cm}$ de lado foi suficiente, já no povoamento de Eucalyptus sp. e na área de Floresta Estacional Decidual, onde foram necessárias muitas amostras para estabilizar o CV $(\%)$, seria conveniente aumentar o tamanho da moldura para $50 \mathrm{~cm}$ de lado, ou mesmo montar parcelas de $1 \mathrm{~m} \mathrm{x} 1 \mathrm{~m}$ ou maior, para se ter uma amostragem mais representativa de cada floresta. Isso poderia facilitar o trabalho de coleta, diminuindo o seu número.

Como as frações que tiveram maior variabilidade na serapilheira acumulada sobre o solo nas três florestas estudadas foram cascas, estruturas reprodutivas e resíduos, seria conveniente juntar essas três frações em uma; com isso se diminuiriam o CV\% e também o número de amostras a serem coletadas, principalmente na área de Floresta Estacional Decidual, onde essas frações sofreram maiores variações.

Com base no método utilizado, o ponto de estabilização da curva de CV\%, que determinou a suficiência amostral necessária, foi de 40 amostras no povoamento de Pinus elliottii, 70 no de Eucalyptos sp. e 80 na área de Floresta Estacional Decidual. Em cada floresta, a partir do número de amostras necessárias não houve diferença estatística entre as médias, do n determinado até o de 100 amostras, calculado a cada aumento de 10 coletas.

\section{REFERÊNCIAS BIBLIOGRÁFICAS}

AMARAL, A.M.; MUNIZ, J. A.; SOUZA, M. Avaliação dos coeficientes de variação como medida da precisão na experimentação com citros. Pesquisa Agropecuária Brasileira, v.32, n.12, p. 1221 - 1225, 1997.

R. Árvore, Viçosa-MG, v.29, n.6, p.965-972, 2005 
FIGUEIREDO FILHO, A. et al. Avaliação Estacional da Deposição de Serapilheira em uma Floresta Ombrófila Mista Localizada no Sul do Paraná. Ciência Florestal, v.13, n. 1, p. 11- 18, 2003.

KLEIN, R. M. Aspectos fitofisionômicos da floresta estacional da fralda da Serra Geral (RS). In: CONGRESSO NACIONAL DE BOTÂNICA, 34. 1983, Porto Alegre. Anais... Porto Alegre, 1983. 2 v. v. 1. p. 73-110.

MACHADO, P. F. S.; LONGHI, S. J. Aspectos florísticos e fitossociológicos do "Morro do Elefante", Santa Maria - RS. Ciência Rural, v. 20, n. 3 - 4. p. 261-280, 1990.
Moreno, J. A. Clima do Rio Grande do

Sul. Porto Alegre: Secretaria da Agricultura, 1961. 73 p.

PIMENTEL - GOMES, F. Curso de estatística experimental. São Paulo: Mc Graw-Hill, 1985. 454p.

STRECK, E. V. et al. Solos do Rio Grande do Sul. Porto Alegre: Universidade Federal do Rio Grande do Sul, 2002. 107 p.

VIBRANS, A.C.; SEVEGNANI, L. Produção de serapilheira em dois remanescentes de floresta ombrófila densa em Blumenau - SC. Revista de Estudos Ambientais. v.2, n. 1, p. 103-116, 2000. 